\title{
DETERMINAÇÃO FOTOMÉTRICA DO FERRO NAS FEZES POR MEIO DO MÉTODO DO ÁCIDO PROTOCATÉQUICO \\ POR
}

\author{
Rubens Salomé Pereira e Arnaldo Costa \\ (Livre docente da Universidade de São Paulo) \\ Comissionado na Fac. Medicina Veterinária
}

Dos trabalhos de ElveHJEm e associados (1) (2) (3) conclue-se que a assimilação do ferro ingerido é tambem variavel dependente dos elementos que constituem a dieta. Coons (4) verificou, ao administrar 9.69 a $19.45 \mathrm{mgr}$. de ferro diariamente, que, exceto num caso em que houve balanço negativo, a retenção oscilava entre $+0.88 \mathrm{e}+6.97 \mathrm{mgr}$. STEENBock (5) achou que os indivíduos do sexo feminino, na maturidade, armazenam maior quantidade desse elemento do que os representantes do sexo masculino. Se bem que ainda haja dúvidas relativas a esse problema, o que parece fora de discussão é o fato de haver largas diferenças em quanto ao aproveitamento do ferro presente nos alimentos.

No estudo do metabolismo do ferro, alem de outros fatores de relevo, dois se devem tomar na devida conta: a forma sob que se encontra o referido elemento na ração - sob forma de composto hemínico, ou não hemínico - e o grau de assimilação do mesmo; e a quantidade desse corpo nos excretos. Como a via principal de eliminação do ferro é a intestinal, é objeto do presente trabalho aplicar o método original de Salomé Pereira (6) à dosagem do referido elemento nas fezes.

\section{MÉTODO}

Preparo do material - As fezes de 24 horas são recolhidas, pesadas no estado úmido, postas a secar à temperatura de $70-72^{\circ} \mathrm{C}$ até que se possam pulverizar facilmente. Determina-se a umidade perdida sob tais condições, reduz-se a substância a pó, passa-se este por peneira de malhas cerradas, recebe-se em pesa-filtro seco e tarado, determina-se o peso do material obtido, leva-se à estufa e seca-se à temperatura de $100^{\circ}-105^{\circ}$ até peso constante. Obteem-se, assim, dois resultados: um que se refere à umidade obtida a baixa temperatura, e outro, à água perdida pela substância parcialmente seca, depois de aquecida a $100^{\circ}-105^{\circ} \mathrm{C}$. Coordenam-se os dois dados e calcula-se a perda total. 
A determinação do ferro total em substâncias orgânicas compreende as duas fases seguintes:

a) incineração do material

b) determinação do ferro na solução das cinzas.

Incineração do material - Tomam-se porções exatamente pesadas, da substância seca, colocam-se em tubos de experiências de vidro Pyrex, graduados à altura de $5-7.5$ e $10 \mathrm{~cm}^{3}$, ajuntam-se $2 \mathrm{~cm}^{3}$ de $\mathrm{SO}_{4} \mathrm{H}_{2}$ $2 \mathrm{n}$, aquece-se o tubo sobre chama pequena, sob agitação contínua, até que se formem abundantes vapores ácidos e que se inicie a carbonização. Deixa-se o tubo esfriar, adiciona-se $0.5 \mathrm{~cm}^{3}$ da mistura nitroperclórica (3 de $\mathrm{NO}_{3} \mathrm{H} d=1.40: 1$ de $\mathrm{Cl} \mathrm{O}_{4} \mathrm{H} d=1.70$ ) e segue-se exatamente a técnica indicada por SALOMÉ PEREIRA (6).

A vista da relativa riqueza de Ca, há quase sempre, no caso presente, precipitado mais ou menos abundante, de $\mathrm{SO}_{4} \mathrm{Ca}$, que deve ser eliminado. Para tanio, ajuntam-se ao tubo graduado $2 \mathrm{~cm}^{3}$ de água destilada, aquece-se até fervura, filtra-se por filtro de vidro poroso, Jena G 3, a solução obtida, e lavam-se o tubo e o filtro 3 ou 4 vezes com água destilada quente. Reunem-se o filtrado e as águas de lavagem em tubo graduado à altura de $10 \mathrm{~cm}^{3}$, esfria-se o soluto assim conseguido e perfaz-se exatamente o volume marcado na parede do vaso. Da solução ácida tomam-se aliquotas convenientes para a determinação do ferro.

Quando o peso da substância incinerada houver sido muito pequeno, é preferivel, após haver-se eliminado o precipitado de $\mathrm{SO}_{4} \mathrm{Ca}$, concentrar-se a solução das cinzas e usar-se a totalidade desta para determinar-se o $\mathrm{Fe}$.

Determinação do ferro na solução das cinzas - Reativos necessários:

a) Citrato de amôneo a $20 \%$

b) Ácido protocatéquico. Solução a $1 \%$ em alcool etílico a $50 \%$

c) Hidróxido de amôneo $2 \mathrm{n}$

d) Solução normal de sulfato de amôneo - solução normal de amoníaco $(4: 1)$.

Quer se tome a totalidade da solução para a dosagem do $F e$, quer se usem aliquotas da mesma, esta, posta em tubo de experiências graduado à altura de $5-7.5$ e $10 \mathrm{~cm}^{3}$, trata-se por $1 \mathrm{~cm}^{3}$ do reativo (a), e em seguida adicionam-se $0.2 \mathrm{~cm}^{3}$ de (b) para cada $5 \mathrm{~cm}^{3}$ de volume total, e, agitando-se o tubo após cada gota ajuntada, o reagente (c), 
cuidadosamente, até que se desenvolva cor vermelha, o que indica haver-se alcalinizado o meio. Por meio do $\mathrm{SO}_{4} \mathrm{H}_{2} \mathrm{n}$, posto cautelosamente às gotas, em quantidade exatamente necessária para atingir o fim em vista, que é acidificar-se levemente o soluto, o que se reconhece pelo desaparecimento da cor vermelha, ou pela transformação desta em violeta, ou em verde-azulada, passa-se para meio ácido a solução das cinzas. Restabelece-se a cor vermelha primitiva por meio do reagente (d), e com este perfaz-se volume conveniente marcado na parede do tubo. Ao mesmo tempo, e exatamente sob as mesmas condiçōes, prepara-se um branco, que servirá de líquido de compensação. Ao cabo de 10-40 minutos determina-se a extinção dada pelo fotômetro de Pulfrich, usando o filtro S-50 e cuba de espessura conveniente.

Resultados - A aplicação do método descrito deu, nos trabalhos em série, os resultados que se reunem nos quadros seguintes:

\section{QUADRO I}

Determinação do $F e$ em fezes de cão por meio do método do ácido protocatéquico (numa só amostra)

\begin{tabular}{r|c|c|c|c|c|c}
\hline $\begin{array}{c}\text { Substâncla } \\
\text { seca } \\
\text { mgr. }\end{array}$ & $\begin{array}{c}\text { Solução das } \\
\text { cinzas } \\
\mathrm{cm}^{3}\end{array}$ & $\begin{array}{c}\text { Parte aliquota } \\
\text { da solução das } \\
\text { cinzas tomaáa } \\
\text { para a análise } \\
\mathrm{cm}^{3}\end{array}$ & $\begin{array}{c}\text { Volume total } \\
\text { da solução } \\
\text { corada } \\
\mathrm{cm}^{3}\end{array}$ & $\mathrm{D}$ & $k$ & $\begin{array}{c}\text { Fe \% na subs- } \\
\text { tânciá seca }\end{array}$ \\
\hline 9.20 & - & - & 10 & 68 & 0.168 & 0.170 \\
17.60 & - & - & 10 & 48 & 0.319 & 0.169 \\
25.60 & 10 & 5 & 10 & 59 & 0.229 & 0.166 \\
20.90 & 10 & 5 & 10 & 65 & 0.187 & 0.166 \\
35.90 & 10 & 5 & 10 & 46 & 0.337 & 0.175 \\
19.80 & 10 & 5 & 10 & 66 & 0.181 & 0.170 \\
9.80 & - & - & 10 & 66 & 0.181 & 0.172 \\
29.10 & 10 & 5 & 10 & 56 & 0.252 & 0.161 \\
33.60 & 10 & 5 & - & 50 & 0.301 & 0.167 \\
\hline
\end{tabular}

MEDIA

\begin{tabular}{|c|c|c|c|c|c|}
\hline ro & 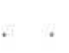 & & & & \\
\hline Idrão & . & . & & & \\
\hline eficiente & & •ฉีం & & & \\
\hline
\end{tabular}




\section{QUADRO II}

Determinação do $\mathrm{Fe}$ em fezes de cão por meio do método do ácido protocatéquico (numa só amostra)

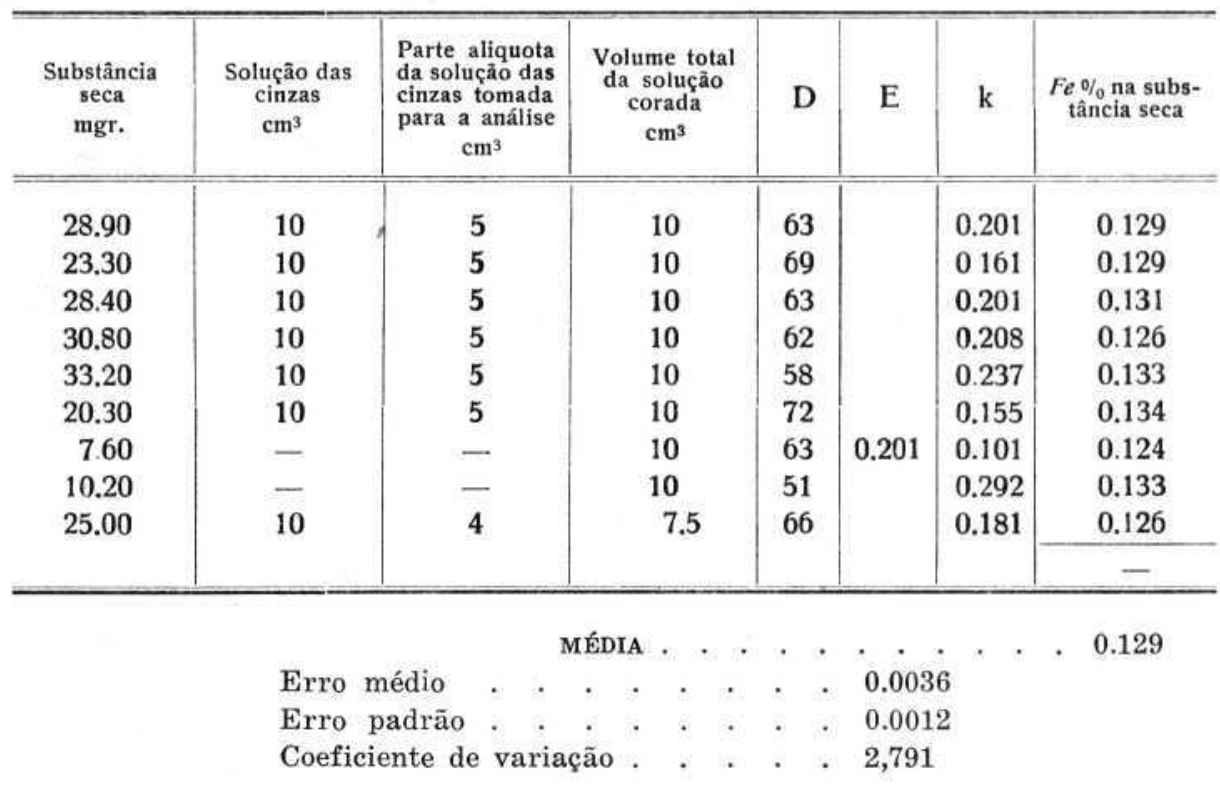

De acordo com os resultados expostos, obtidos em trabalhos em série, o método do ácido protocatéquico é perfeitamente seguro - e, portanto, aconselhavel - para o fim de determinar-se o ferro nas fezes. É, alem disso, rápido, sensivel e econômico.

\section{SUMMARY}

The photometric method for iron described by SALOMÉ PEREIRA (1941) has been successfully applied to the determination of iron in faeces.

Results are given.

\section{BIBLIOGRAFIA}

1) Elvehjem, C. A., Hart, E. B., e Sherman, W. C. - 1933-Journ. Biol. Chem. 103: 61 .

2) Sherman, W. C., Elvehjem, C. A., e Hart, E. B. - 1934 - Journ. Biol. Chem. 107: 289 .

3) Sherman, W. C., Elvehjem, C. A., e Hart, E. B. - 1934 - Journ. Biol. Chem. 107: 383 .

4) Coons, C. M. - 1932 - Journ. Biol. Chem. 97: 215.

5) Steenbock, H. - 1936 - Journ. Biol. Chem. 114: CI.

6) Salomé Pereira, R. - 1941 - Journ. Biol. Chem. 137: 417. 